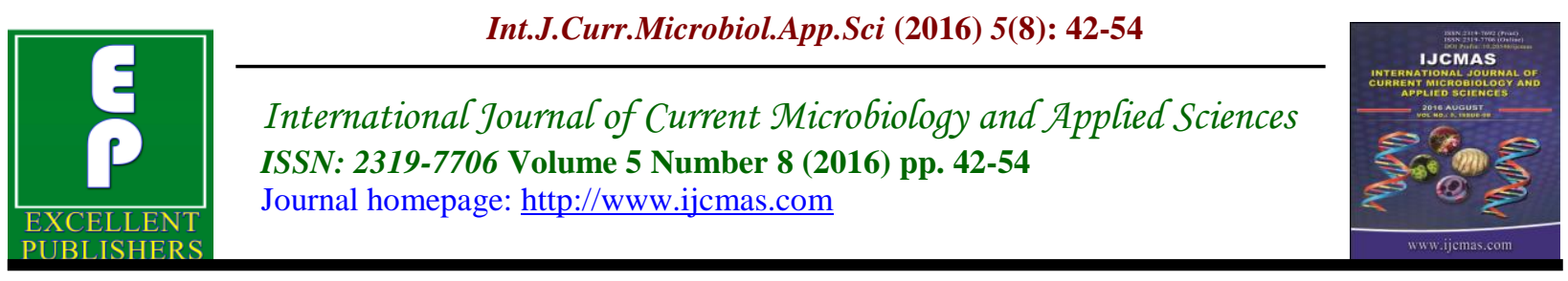

Original Research Article

http://dx.doi.org/10.20546/ijcmas.2016.508.005

\title{
Comparative Study of Antioxidant Potential in Hairy Roots and Field grown Roots of Solanum nigrum $\mathbf{L}$.
}

\author{
Subhash Kudale $^{1}$, Swaroopa Ghatge ${ }^{2}$, Anuja Shivekar ${ }^{1}$, Chinmyee Sule ${ }^{1}$ and Neetin Desai ${ }^{3 *}$ \\ ${ }^{1}$ School of Biotechnology and Bioinformatics, D.Y. Patil University, \\ Navi Mumbai 400614, India \\ ${ }^{2}$ Department of Botany, Shivaji University, Kolhapur-416004, India \\ ${ }^{3}$ Amity School of Biotechnology, Amity University, Mumbai-410206, India \\ *Corresponding author
}

Keywords

Alkaloids, flavonoids, hairy roots, antioxidant, DPPH, FRAP, ABTS, SO, Solanum nigrum $\mathrm{L}$.

\section{Article Info}

Accepted:

06 July 2016

Available Online:

10 August 2016

\section{A B S T R A C T}

Field grown roots (FGR) and hairy roots (HR) were compared for total phenolics, flavonoids and antioxidant capacity using three different solvents. The aqueous and ethanolic extract showed high phenolic $(9.036 \pm 0.613)$ and flavonoids $(25.392 \pm 0.687)$ content in HR compared to FGR respectively. High alkaloid content was observed in ethanolic extract of HR (23.628 \pm 0.907$)$. The aqueous extract showed maximum DPPH, ABTS and SO radical scavenging antioxidant activity in HR compared to FGR. The highest Frap value (1.88) was observed for aqueous extract in HR. The ethanol and water was found to be best for the extraction of flavonoids and antioxidant compounds respectively. HR showed high content of biochemical than the FGR.

\section{Introduction}

Solanum nigrum (black nightshade) is a medicinal plant member of the Solanaceae family. This family comprises many genera, well known for their therapeutic properties. It occurs on a wide range of soils but prefers soil rich in nitrogen. Solanum nigrum Linn. is commonly used in the traditional medicine as a remedy for treating various ailment such a pain, inflammation and fever (Zakaria et al., 2006.). Solanum nigrum is also used as antitumorigenic, antioxidant (Lee et al., 2003), anti-inflammatory, diuretic, antipyretic agent (Zakaria et al., 2006), hepatoprotective (Raju et al., 2003), anticancer, immunomodulatory (Jian et al., 2009), larvicidal (Ahmed et al., 2002), hepatoprotective (Raju et al., 2003) and antibacterial (Rani et al., 2004). It has been used against sexually transmitted diseases as well (Atanu et al., 2011). The species exhibits a high level of morphological plasticity and several subspecies have been identified. The plant and berries can form a sticky mass during harvesting operations. 
The leaves are used to heal open wounds and is known to possess hypotensive effect. The toxicity of black nightshade due to the alkaloid Solanine has caused varying degrees of poisoning in humans, cattle, pigs and goats (Cooper and Johnson, 1984). Although it is considered a rich source of one of the most popular plant poisons, it has also proven to be a reservoir of phytochemicals with phamacological prospects (Lee and Lim, 2006). Solasodine has been reported as a valuable steroidal precursor for the supplementary source of the commercial synthesis of several steroidal drugs (Rodriguez et al., 1979; Sree et al., 1982). It could be primarily obtained from various plants of genus Solanum (Crabbe and Fryer, 1982). Subroto et al., (1994) reported that the solasodine content was increased by 5 times in hairy root compared to normal plant. Due to the importance and presence of solasodine in hairy roots, few reports are available on hairy root induction in solanum species (Khatodia and Biswas, 2014; Pawar and Maheshwari, 2004; Ooi, 2012). The active components are polyphenolics, polysaccharides such as gallic acid, cathechin, caffic acid, rutin (Chauhan et al., 2012).

In present study, we have intended to evaluate and compare the antioxidant potential between $\mathrm{HR}$ and FGR with the help of total phenolics, flavonoids and alkaloids and have also performed the free radical scavenging activity by $\mathrm{DPPH}$, ABTS, FRAP and SO assays. There is no report available on comparative study in hairy root and field grown roots for antioxidant activity.

\section{Materials and methods}

\section{Reagent and standards}

Ascorbic acid, ferric chloride, aluminium trichloride, sodium bicarbonate, 1,10phenanthroline, folin-ciocalteu reagent, rutin, colchicines, DPPH, TPTZ and ABTS were purchased from Sigma chemicals USA and NADH, NBT and PMS from Hi-Media.

\section{Sample Preparation}

Extraction of samples was performed in a similar way as described by Chaturvedi et al., 2011. The dry FGR and HR of Solanum nigrum (Fig. 1) was crushed using liquid nitrogen. Fine root powder was suspended in $100 \mathrm{ml}$ of three different solvents (Water, Methanol and Ethanol) and kept on shaker for overnight. The extracts were filtered through the muslin cloth and centrifuged at $10,000 \mathrm{rpm}$ for 10 minutes. The supernatant was collected and condensed to $10 \mathrm{ml}$ on rotary evaporator and stored at $4^{\mathrm{O}} \mathrm{C}$. Further extracts were tested for Total Phenolics, flavonoids and antioxidant activity.

\section{Determination of total phenolic content (TPC)}

The total phenolics content from all the extracts was determined using Singleton and Rossi (1965) method. The reaction mixture was prepared by adding $0.125 \mathrm{ml}$ of $1 \%$ plant extract and $1.8 \mathrm{ml}$ of Folin-Ciocalteu reagent. The assay mixture was incubated for $5 \mathrm{~min}$ at room temperature. $1.2 \mathrm{ml}$ of aqueous sodium carbonate was added to the mixture and was kept in dark for $90 \mathrm{~min}$ at room temperature. Phenolic content of these samples was determined spectrophotometrically using a UV visible spectrophotometer at $760 \mathrm{~nm}$. The total phenolics content was quantified with standard curve of gallic acid and total content was expressed as mg of gallic acid equivalents per $\mathrm{g}$ of roots.

\section{Determination of total flavonoids content (TFC)}

The total flavonoids content from all the extracts was determined using Luximan- 
Ramma et al., (2002) method. The reaction mixture contains $1.5 \mathrm{ml}$ of $1 \%$ extract and $1.5 \mathrm{ml}$ of $2 \%$ methanolic aluminum chloride. The reaction mixture was incubated for 10 min at room temperature. The absorbance was measured at $368 \mathrm{~nm}$ in UV-visible spectrophotometer. The total flavonoids content was quantified with standard curve of rutin and total content was expressed as $\mathrm{mg}$ of rutin equivalents per $\mathrm{g}$ of roots.

\section{Determination of total alkaloids content (TAC)}

The total alkaloid content from all the extracts was determined using the method of Singh et al., (2004). The reaction mixture contains $1 \%$ extract, $1 \mathrm{ml}$ of $0.05 \mathrm{M}, 1-10$ phenanthroline reagent and $1 \mathrm{ml}$ of $0.025 \mathrm{M}$ ferric chloride. After addition of all reagent mixture was incubated at $70^{\circ} \mathrm{C}$ in water bath for $30 \mathrm{~min}$. The absorbance was recorded at $510 \mathrm{~nm}$. The total alkaloids content was quantified comparing with standard curve of colchicine and total content was expressed as $\mathrm{mg}$ of colchicine equivalents per gm of root.

\section{Determination of DPPH radical scavenging activity}

The free radical scavenging activity was estimated using DPPH as described by Ghatak et al., 2014. The assay mixture contains $0.5 \mathrm{~mL}$ of $0.3 \mathrm{mM}$ DPPH solution and $100 \mu \mathrm{L}$ respective extracts. The mixture was kept in dark at $37^{\circ} \mathrm{C}$ for $30 \mathrm{~min}$. The absorbance was measured at $517 \mathrm{~nm}$ by spectrophotometer. The ability to scavenge DPPH radical was calculated using following formula:

\footnotetext{
Absorbance of the control - Absorbance of sample$$
\% \text { Inhibition }=\quad \text { - -------------------X } 100
$$

\section{Ferric reducing antioxidant power (FRAP) assay}

FRAP assay was carried out according to the method of Jain et al., 2014. FRAP reagent was prepared using sodium acetate buffer (1.6g sodium acetate and $8 \mathrm{ml}$ acetic acid make up to $100 \mathrm{~mL}$ ) (pH 3.6), $10 \mathrm{mM} \mathrm{2,4,6-}$ Tripyridyl-s-Triazine (TPTZ) solution in 40 $\mathrm{mM} \mathrm{HCl}$ and $20 \mathrm{mM}$ ferric chloride solution in proportion of 10:1:1 (v/v) respectively. The FRAP reagent was prepared fresh. $100 \mu \mathrm{L}$ extracted samples were added to 3 $\mathrm{mL}$ of the FRAP reagent and mixed well. The absorbance was measured at $593 \mathrm{~nm}$ at 0 min and after 4 min using FRAP reagent as blank. Standard curve of ascorbic acid was prepared. FRAP value of sample was calculated.

\section{ABTS radical scavenging assay}

ABTS assay was carried out using the method described by Pai et al., 2015. Stock solutions of $7 \mathrm{mM}$ ABTS and $2.4 \mathrm{mM}$ potassium persulfate/ ammonium persulfate were prepared. The working stock was prepared by mixing both solutions in equal quantities and incubated in dark for $12 \mathrm{~h}-16 \mathrm{~h}$ at $30^{\circ} \mathrm{C}$. The incubated solution was diluted by methanol to obtain 0.706 OD at $734 \mathrm{~nm}$. Each plant extract were mixed with diluted ABTS solution in equal quantity and the OD was taken at $734 \mathrm{~nm}$ after $7 \mathrm{~min}$. by spectrophotometer. The ABTS scavenging capacity of the extract was calculated as:

ABTS radical scavenging activity $(\%)=$

Abs. of control - Abs. of sample

--------------------------------× 100

Abs. of Control 


\section{Superoxide radical scavenging assay}

The superoxide radical scavenging assay was performed as per Mandal et al., 2009. The assay mixture contains $1 \mathrm{~mL}$ of root extract, $\quad 0.5 \mathrm{~mL} \quad(0.3 \mathrm{mM}) \quad$ Nitro blue tetrazolium (NBT), $0.5 \mathrm{ml}$ Nicotinamide adenine dinucleotide $(\mathrm{NaDH})(0.936 \mathrm{mM})$, TrisHCl Buffer $(16 \mathrm{mM}) \quad(\mathrm{pH}-8.0)$ and Phenazinemethosulphate (PMS) $(0.12 \mathrm{mM})$. The reaction mixture was kept for incubation at $25^{\circ} \mathrm{C}$ for 5 min. After incubation absorbance was measured by spectrophotometer at $560 \mathrm{~nm}$. The superoxide scavenging activity was calculated as:

Superoxide radical scavenging activity $(\%)=$

Abs. of control - Abs. of sample

Abs. of Control

\section{Statistical analysis}

All the observations were taken in triplicate and the data was presented as \pm standard deviation (SD). Analysis of Variance (one way ANOVA) was further performed using SPSS software.

\section{Result and Discussion}

\section{Total phenolic content}

FGR (6.950 $\left.\pm 0.436 \mathrm{mg} \mathrm{GAE}^{-1}\right)$ and HR

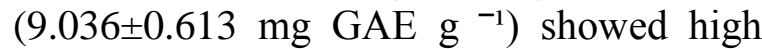
phenolic content in aqueous extract where as lowest phenolics was observed in ethanolic extracts $(0.786 \pm 0.022$ and $2.892 \pm 0.613 \mathrm{mg}$ GAE $\mathrm{g}^{-1}$ ) respectively (Table no. 1). Water found to be best solvent compared to other for the extraction of phenolic compounds. We also observed that HR show high phenolic content as compared to the FGR. Similar results also reported by Jayachitra A and Kritiga N (2012), in which aqueous extract of Solanum nigrum showed $14 \mathrm{mg}$ of phenolics. In another study Solanum melongena also showed similar result in which they found $0.611 \mathrm{mg}$ of phenolic content (Somavati et al., 2014). Ghosal M and Mandal P (2012) also reported the same result, in which two plants, Solanum anguivi and Solanum incanum showed 1.606 and $2.306 \mathrm{mg}$ of phenolic content respectively.

\section{Total flavonoids content}

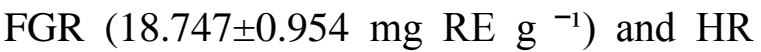

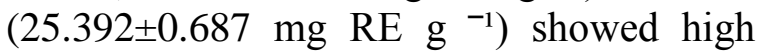
flavonoids content in ethanolic extract where as lowest flavonoids was observed in methanolic extracts $(7.675 \pm 0.376$ and $9.640 \pm 0.277 \mathrm{mg}$ RE $\mathrm{g}^{-1}$ ) respectively (Table no. 2). Ethanol was found to be best solvent compared to other for the extraction of flavonoids compounds. The HR showed high flavonoids content than the FGR. Ghosal M and Mandal P (2012) reported the same in which two plants Solanum anguivi and Solanum incanum showed 0.101 and $0.207 \mathrm{mg}$ of flavonoid content respectively. In another study of Solanum muricatum the flavonoids content was found to be 53.60 mg (Sudha et al., 2011).

\section{Total alkaloid content}

The highest alkaloids content was observed in HR. The ethanolic extract showed high alkaloid content in HR $(23.628 \pm 0.907 \mathrm{mg}$ $\left.\mathrm{CE} \mathrm{g}^{-1}\right)$ as well as in FGR $(12.036 \pm 1.134$ $\mathrm{mg} \mathrm{CE} \mathrm{g}^{-1}$ ) where as lowest alkaloids was observed in methanolic extract $(5.621 \pm 1.026$ and $4.02 \pm 0.641 \mathrm{mg} \mathrm{CE}^{-1}$ ) respectively (Table no. 3). For the extraction of alkaloids the ethanol solvent was found best compared to other solvent. HR showed high alkaloid content than the FGR. Sundari et al., (2013) reported the same kind of result in three different species of Solanum, S. trilobactum, $S$. torvum and $S$. xanthocarpum showed $(6.12, \quad 5.30$ and $4.70 \mathrm{mg} / \mathrm{g})$ of alkaloids content respectively. 


\section{Estimation of DPPH radical scavenging activity}

The DPPH method has been widely used to evaluate the free radical scavenging ability of antioxidants. Plants are the potential source of natural antioxidants and produce antioxidative compounds in order to survive and counteract with reactive oxygen species (Huda et al., 2009). The method is based on scavenging of DPPH radicals by antioxidant compounds from plant that decolourizes the DPPH solution. The colour change can be proportional to the potency and concentration of antioxidants (Saeed et al., 2012). The present study shows that DPPH radical scavenging activity was highest in aqueous extracts of FGR $(51.339 \pm 1.107 \%)$ and HR (86.377 $\pm 1.310 \%)$ (Fig.2). Methanolic and ethanolic extracts showed less antioxidant activity. The HR showed high DPPH radical scavenging activity than the FGR. The aqueous extracts were found best in DPPH radical scavenging activity in both FGR and HR. Similar study was performed on Solanum nigrum plant by Sharma et al., (2014) in which they showed that chloroform extract have highest $(68.74 \pm 0.37 \%)$ radical scavenging capacity. In comparison to Saraka asoka in which Methanolic exract showed higest (94.4 $\pm 1.2 \%)$ DPPH activity (Ghatak et al., 2015) where as $88 \%$ DPPH activity was observed in Citrullus colocynthis (Kumar et al., 2008). In another study six plants species of solanum were campaired for DPPH activity in which ethyl acetate extract of Solanum anguivi showed maximum activity (Gandhhipan and Rengasamy, 2012).

\section{Estimation of FRAP radical scavenging activity}

FRAP assay measures the amount of antioxidants based on its ability to reduce
$\mathrm{Fe} 3+$ to Fe2. In FGR the aqueous extract showed highest $(1.076 \pm 0.135)$ frap value where as lowest $(0.280 \pm 0.036)$ frap value was observed for ethanolic extract (Fig. 2). In case of HR the highest frap value was observed for aqueous extract $(1.884 \pm 0.097)$ and lowest for Methanolic extract $(0.536 \pm 0.043)$ (Fig. 3). Similar kind of result was observed in Saraca asoca, high frap value $(2.83 \pm 0.8)$ was observed for ethanolic extract (Ghatak et al., 2014). In comparison of both roots the HR shows high frap value than the FGR. From the above result the aqueous solvent was found to be best for FRAP antioxidant activity. Similar result were reported in Helicterus isora, in which they found aqueous solvent is best for FRAP antioxidant activity (Jain et al., 2014). In another study the ethanolic extract of Saraca indica showed highest frap value (Gayatri $e t$ al., 2013).

\section{Estimation of ABTS radical scavenging activity}

The ABTS radical cation is generated by the oxidation of ABTS with potassium persulfate, its reduction in the presence of hydrogen-donating antioxidants is measured spectrophotometrically at $734 \mathrm{~nm}$ (Saeed et al., 2012). The aqueous extract of FGR showed highest $(69.61 \pm 0.739 \%)$ ABTS scavenging activity followed by Methanolic and ethanolic extract (Fig. 4). In HR aqueous extract showed highest (92.751 $\pm 1.452 \%)$ ABTS radical scavenging activity (Fig. 3). In both FGR and HR the highest and lowest antioxidant activity was observed in aqueous and ethanolic extract respectively. Comparatively HR showed high antioxidant activity than the FGR. These result were similar to the study performed by Somawati et al., (2014), they showed that aqueous extract of solanum melongena shows $40.45 \%$ activity. In other study the Methanolic extract of Solanum 
pseudocapsicum also showed $49.66 \%$ antioxidant activity (Badami et al., 2005). Sudha et al., (2011) showed that ethyl acetate extract of Solanum muricatum have the $98 \%$ antioxidant activity. In another study the ethanolic and aqueous extract of Solanum nigrum showed 94.06 and $85.62 \%$ ABTS radical scavenging antioxidant activity respectively (Gbadamosi and Afolayan, 2016).

\section{Estimation of Superoxide radical scavenging activity}

In the PMS-NADH-NBT system, superoxide anion was derived from dissolved oxygen by PMS-NADH coupling reaction and reduces NBT. The decrease of absorbance at $560 \mathrm{~nm}$ with antioxidants indicates the consumption of superoxide anion in the reaction mixture (Muruhan et $a l ., 2013)$. In the present study the aqueous extract of HR and FGR $(62.68 \pm 2.078$ and $52.31 \pm 1.801 \%$ ) showed maximum superoxide radical scavenging activity respectively (Fig. 5). The ethanolic and methanolic extract showed lowest SO activity respectively. The HR were found best for Superoxide radical scavenging activity in comparison with FGR. The aqueous solvent was observed best for extraction of antioxidant compounds. The same study was performed by Gandhiappan et al., (2012), in which they found $9.427 \%$ activity for $S$. anguivi. In another study the same result was observed for $S$. surattense, they observed $65 \%$ SO scavenging activity (Muruhan et al., 2013). Backialakshmi et al., (2015) also reported that ethanolic extract of $S$ nigrum shows $50 \%$ Superoxide radical scavenging activity at $5.9 \mu \mathrm{g} / \mathrm{ml}$.

Table.1 Total phenolics content

\begin{tabular}{|l|c|c|c|}
\hline Solvent/plant material & Water & Ethanol & Methanol \\
\hline Field grown root & $6.950 \pm 0.436$ & $0.786 \pm 0.022$ & $1.071 \pm 0.085$ \\
\hline Hairy root & $9.036 \pm 0.613^{* *}$ & $2.892 \pm 0.613^{* *}$ & $4.229 \pm 0.085^{* *}$ \\
\hline
\end{tabular}

Table.2 Total flavonoid content

\begin{tabular}{|l|c|c|c|}
\hline Solvent/plant material & Water & Ethanol & Methanol \\
\hline Field grown root & $11.301 \pm 0.259$ & $18.747 \pm 0.954$ & $7.675 \pm 0.376$ \\
\hline Hairy root & $15.910 \pm 1.939 * *$ & $25.392 \pm 0.687 * *$ & $9.640 \pm 0.277 * *$ \\
\hline
\end{tabular}

Table.3 Total alkaloid content

\begin{tabular}{|l|c|l|c|}
\hline Solvent/plant material & Water & Ethanol & Methanol \\
\hline Field grown root & $4.647 \pm 0.319$ & $12.036 \pm 1.134$ & $4.02 \pm 0.641$ \\
\hline Hairy root & $9.250 \pm 0.812^{* *}$ & $23.628 \pm 0.907 * *$ & $5.621 \pm 1.026$ \\
\hline
\end{tabular}


Fig.1 a. Solanum nigrum L., b. Entire Solanum nigrum plant with roots, c. Hairy roots, d. PCR confirmation of hairy roots.
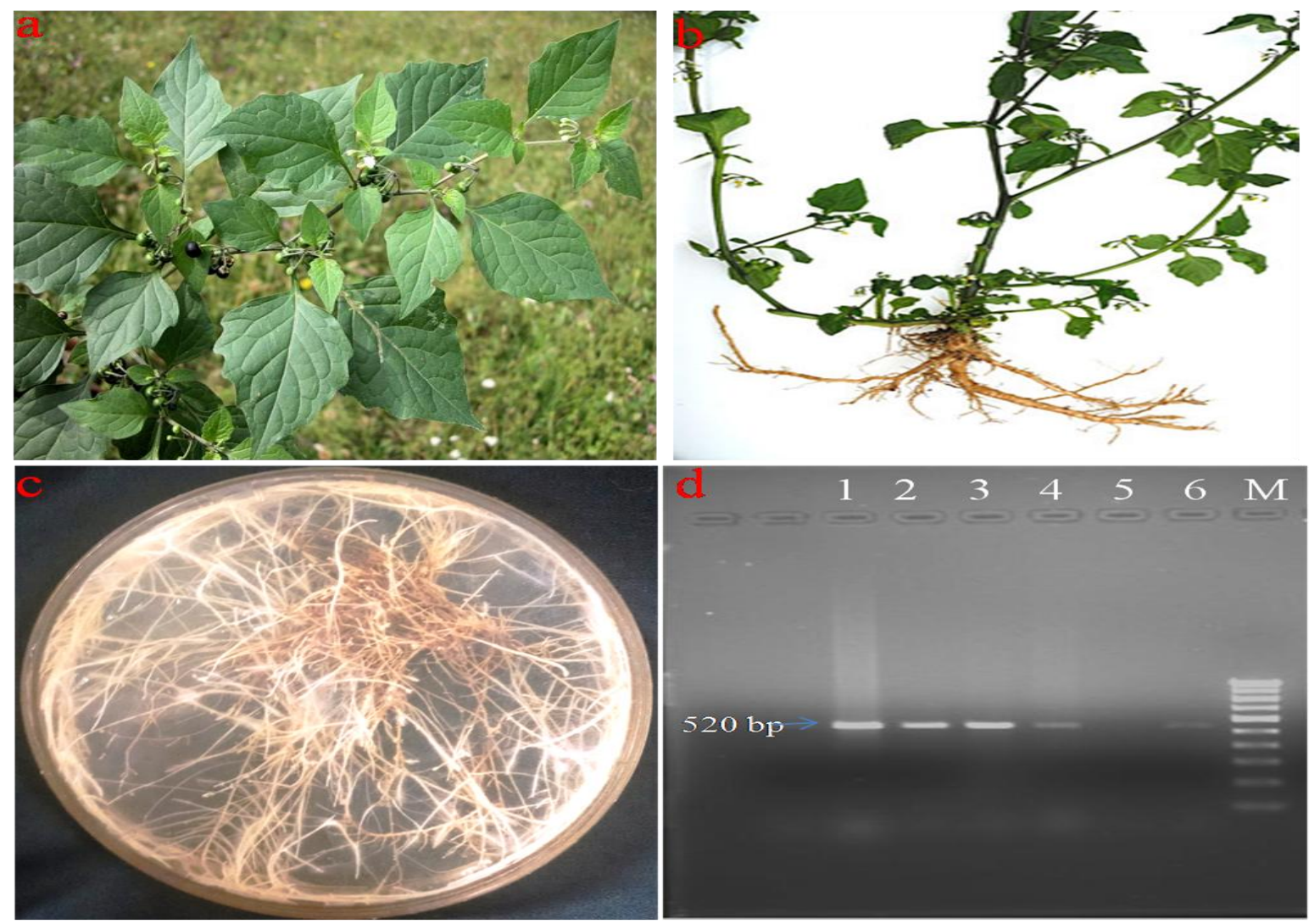

Fig.2 Percent DPPH radical scavenging activity of Solanum nigrum.

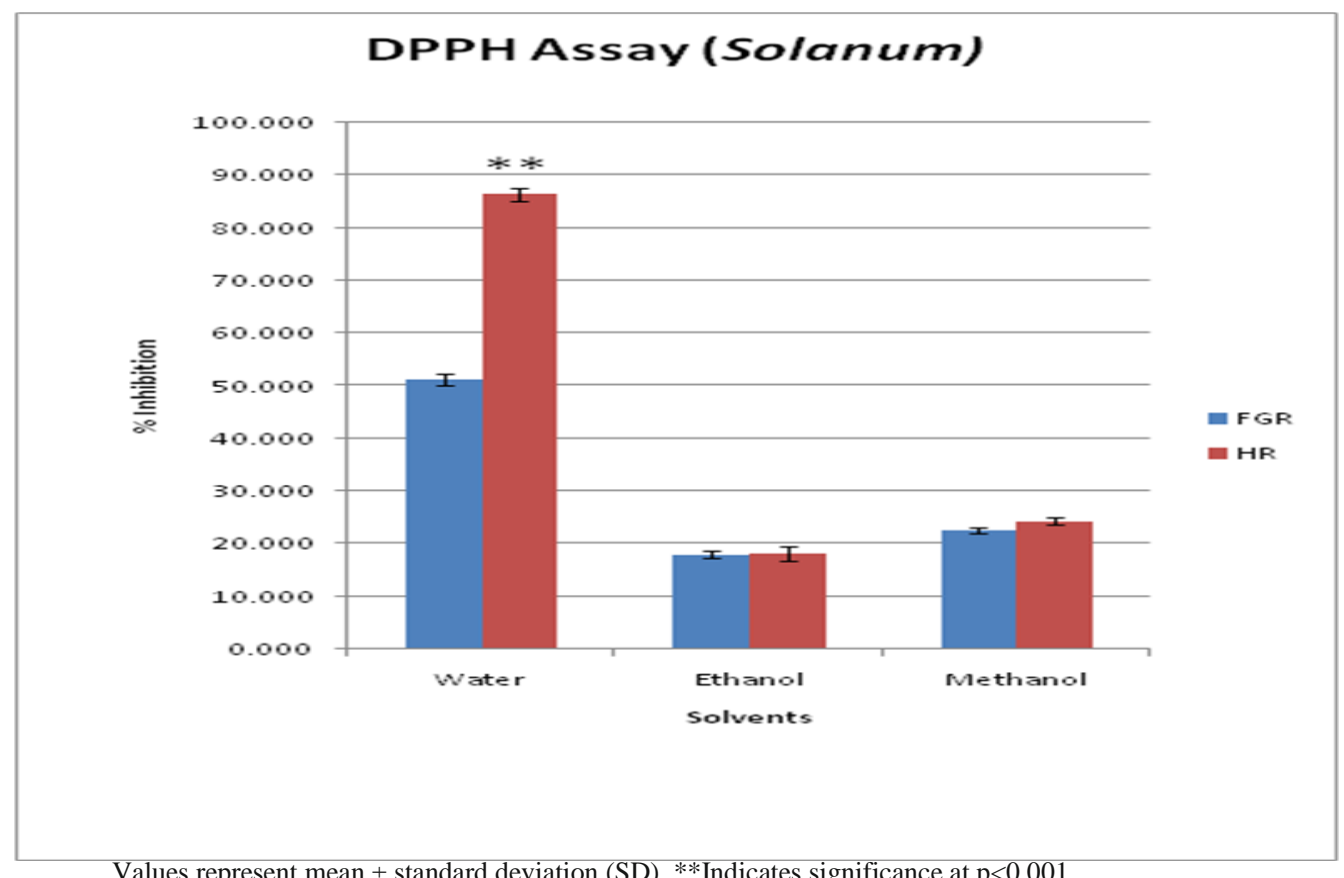

Values represent mean \pm standard deviation $(\mathrm{SD})$, **Indicates significance at $\mathrm{p}<0.001$ 
Fig.3 FRAP radical scavenging activity of Solanum nigrum.

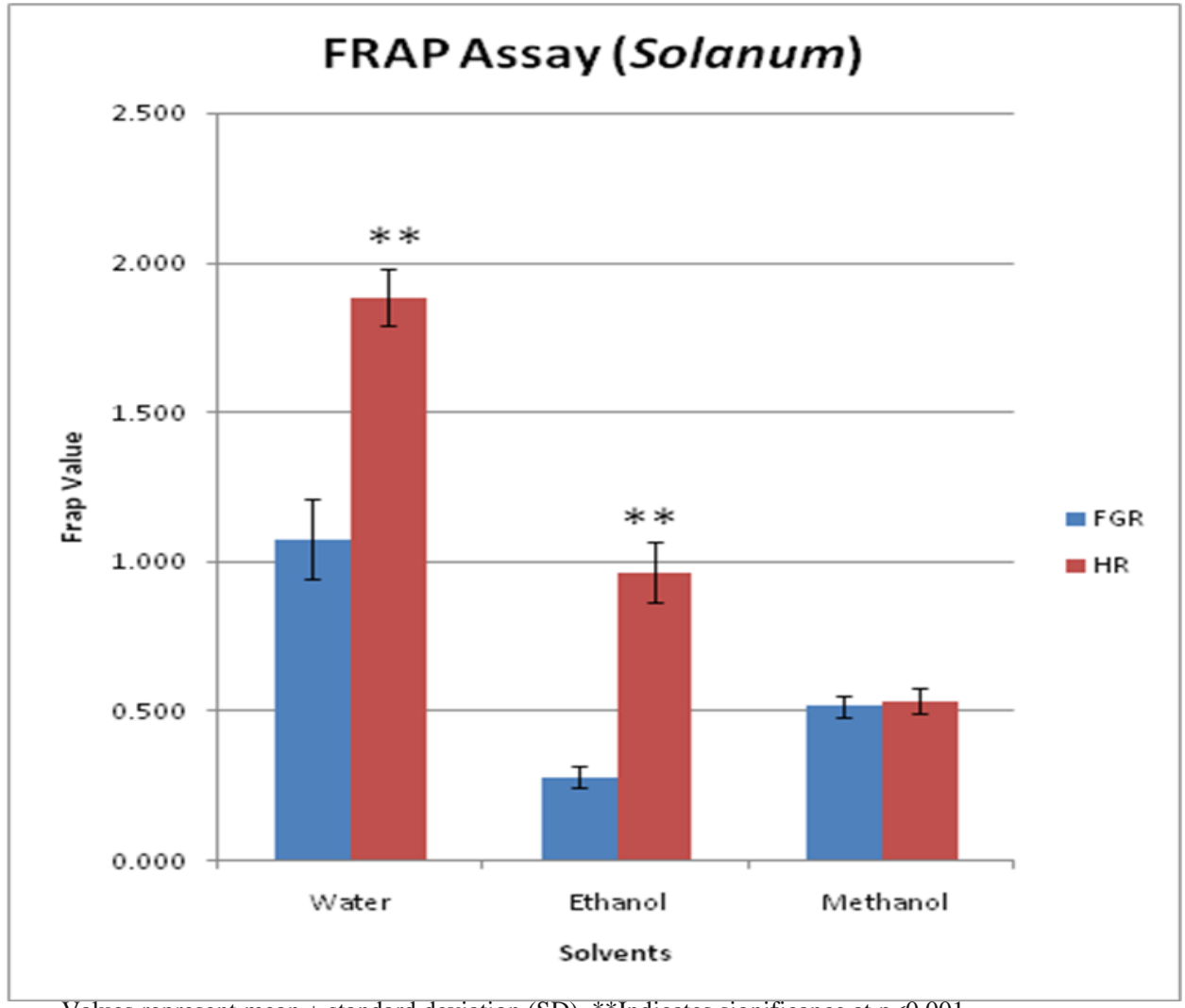

Values represent mean \pm standard deviation $(\mathrm{SD}),{ }^{* *}$ Indicates significance at $\mathrm{p}<0.001$

Fig.4 Percent ABTS radical scavenging activity of Solanum nigrum.

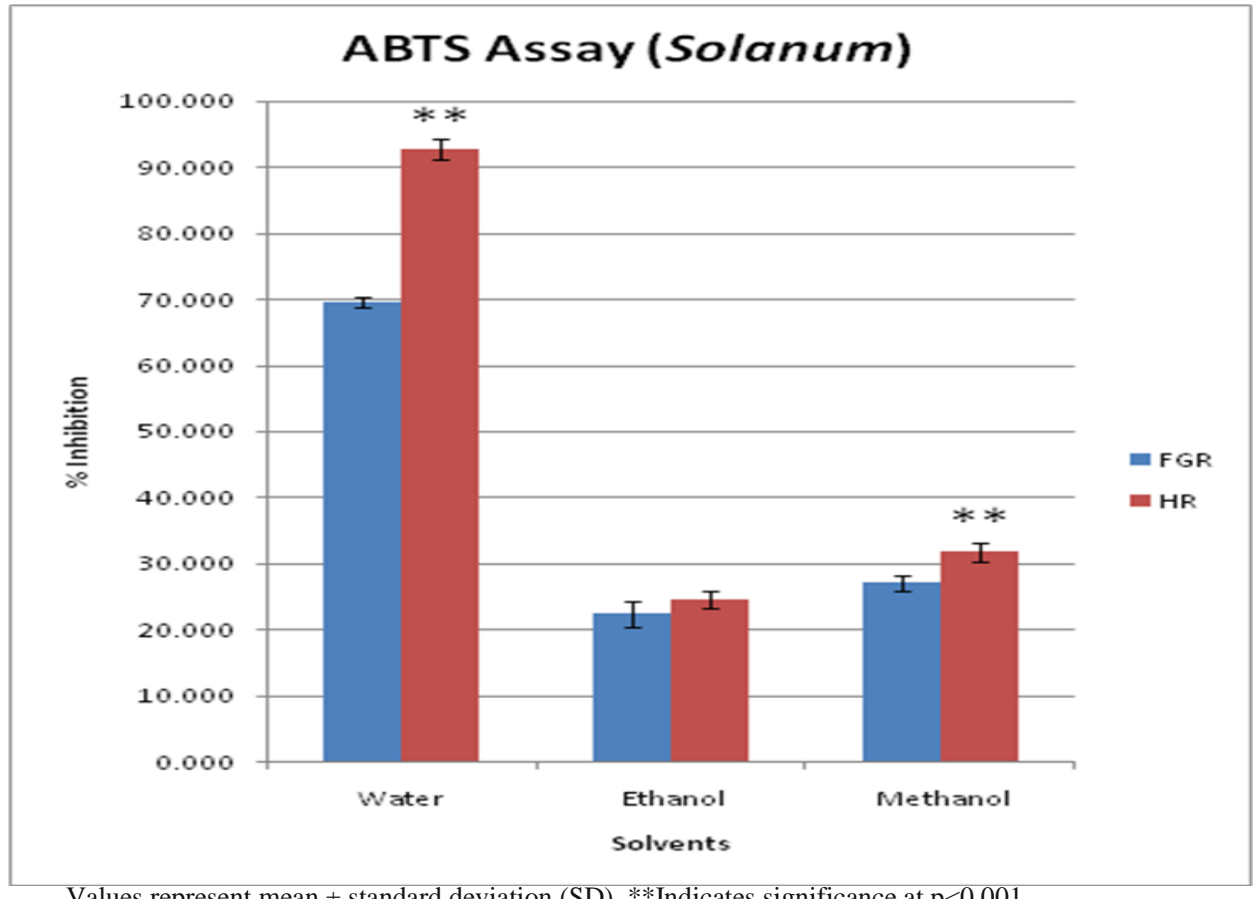

Values represent mean \pm standard deviation $(\mathrm{SD}),{ }^{* *}$ Indicates significance at $\mathrm{p}<0.001$ 
Fig.5 SO radical scavenging activity of Solanum nigrum.

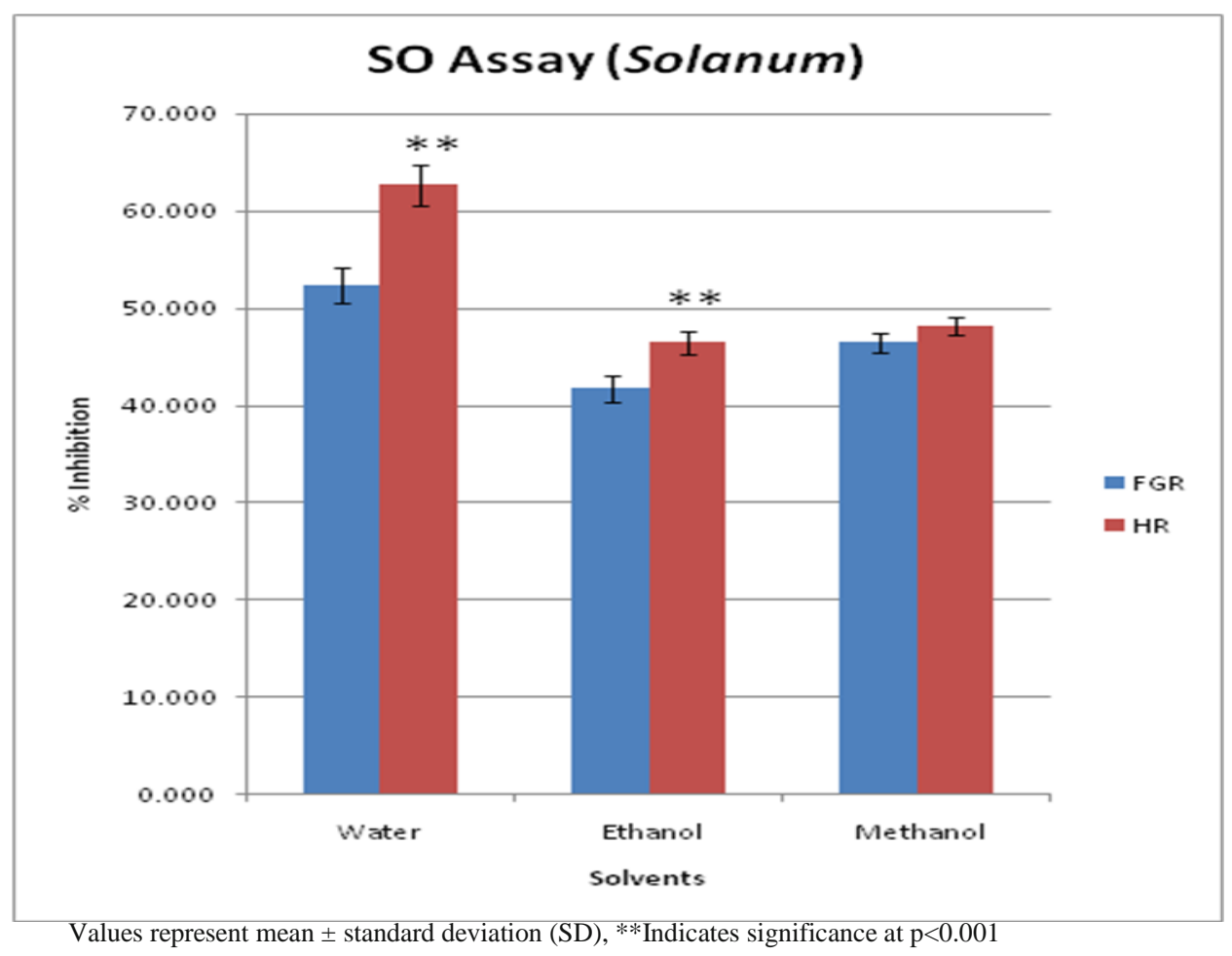

Hairy Root Culture technique was developed as the new source for large scale secondary metabolite production (Flores $e t$ al., 1987; Rhodes et al., 1987) and production of phytochemicals (Shanks and Morgan, 1999). Hairy roots (HRs) are characterized by rapid growth and extensive branching in growth regulator free medium. In general, they exhibit genetic stability and, in certain cases, they have the capability of synthesizing secondary metabolites normally present in roots and organs of the species of origin. For this reason, hairy roots have been induced in several medicinal and aromatic plants and cultured for the production of secondary compounds (Bonhomme et al., 2000; Murthy et al., 2008; Khatodia et al., 2014). The secondary metabolites play an important role in antioxidant capacity of any plant and it has been proved by present study. In the present study the HR showed high antioxidant activity than the FGR which indicates the high content of secondary metabolite present in hairy root. Also it the first report of comparative study for antioxidant activity in HR and FGR. Many reports are available on presence of Solasodine an precursor of commercially important steroid (Subroto et al 1994; Jacob et al 2004; Loc et al.,), in solanum species so the present report will help for the production of root biomass and secondary metabolite (solasodine) on large scale.

In conclusion, in the present study FGR and HR is compared for antioxidant activity. We observed significant increase in accumulation of different important Phytochemicals like phenolics and flavonoids in hairy roots. We also observed a significant increase in antioxidant radical scavenging activity of the HR in comparison of FGR. HR may be considered as good source of natural antioxidant as compared to FGR. Further investigation also lead us to 
conclude that Water is the best solvent system for the extraction of antioxidant compounds compared to other solvent system. It has been proved that HR accumulate higher amount of metabolites than the FGR. The result from this investigation indicates that HR of $S$. nigrum exhibits excellent scavenging activity against free radicals such as DPPH, FRAP, ABTS and Superoxide anion. The present findings of the study suggested that HR of Solanum nigrum could be a potential source of natural antioxidant that could replace the use of toxic synthetic antioxidants.

\section{Acknowledgements}

Authors are thankful to higher authority of D. Y. Patil University, School of Biotechnology and Bioinformatics for providing necessary facilities.

\section{References}

Ahmed, A.H., Kamal, I.H., Ramzy, R.M. 2002. Studies on the molluscicidal and larvicidal properties of Solanum nigrum L. leaves ethanol extract. $J$. Egyptian Soc. Parasitol., 31(3): 843852.

Atanu, F.O., Ebiloma, U.G. and Ajayi, E.I. 2011. A review of the pharmacological aspects of Solanum nigrum L. Biotechnol. Mol. Biol. Rev., 6(1): 001-007.

Backialakshmi, S., Kalaimathi, J. 2015. Preliminary phytochemical analysis and in vitro antioxidant activity of aqua alcoholic extract of Solanum nigrum leaves. Indo American $J$. Pharma. Sci., 2(7):1126-1132.

Badami, S., Prakash, O., Dongre, S. and Suresh, B. 2025. In vitro antioxidant properties of Solanum pseudocapsicum leaf extracts. Indian J. Pharmacol., 37(4): 251-252.
Bonhomme, V., Laurain-Mattar, D., Lacoux, J., Fliniaux, M., Jacquin-Dubreuil, A., 2000. Tropane alkaloid production by hairy roots of Atropa belladonna obtained after transformation with Agrobacterium rhizogenes 15834 and Agrobacterium tumefaciens containing rol A, B, C genes only. J. Biotechnol., 81: 151-158.

Chaturvedi, P.A., Ghatak, A.A. and Desai, N.S. 2011. Evaluation of radical scavenging potential of Woodfordia fruticosa from different altitudes. $J$. Plant Biochem. Biotech., 17: 17-22.

Chauhan, R., Ruby, K., Shori, A. and Dwivedi, J. 2012. Solanum nigrum with dynamic therapeutic role: A review. Int. J. Pharma Sci. Rev. Res., 15(1): 65-71.

Cooper, M.R. and Johnson, A.W. 1984. Poisonous Plants in Britain and other effects on Animals and Man. Ministry of Agri. Fisheries Food, 161: 219-220.

Crabbe, P.G. and Fryer, C. 1982. Evaluation of chemical analysis for the determination of solasodine in Solanum laciniatum. J. Pharm. Sci., 71: 1356-1362.

Flores, H., Hoy, M., Pickard, J., 1987. Secondary metabolites root cultures. Trends in Biotechnol., 5: 64-65.

Gandhiappan, J., Rengasamy, R. 2012. Comparative study on antioxidant activity of different species of Solanaceae family. Adv. Appl. Sci. Res., 3(3): 1538-1544.

Gayathri, P. and Jeyanthi, G.P. 2013. Radical scavenging activity of Saraca indica bark extracts and its inhibitory effect on the enzymes of carbohydrate metabolism. Int. J. Chem. Pharm. Sci., 4: 87-96.

Gbadamosi, I. and Afolayan, A. 2016. In vitro anti-radical activities of extracts of Solanum nigrum (L.) from South Africa. J. Appl. Biosci., 98: 9240 - 
9251.

Ghatak, A.A., Chaturvedi, P.A. and Desai, N.S. 2014. Indian Grape Wines: A Potential Source of Phenols, Polyphenols, and Antioxidants. Int. J. Food Prop., 17: 818-828.

Ghatak, A., Nair, S., Vajpayee, A., Chaturvedi, P., Samant, S., Soley, K., Kudale, S. and Desai, N. 2015. Evaluation of antioxidant activity, total phenolic content, total flavonoids, and LC-MS characterization of Saraca asoca (Roxb.) De. Wilde Int. J. Adv. Res., 3(5): 318-327.

Ghosal, M. and Mandal, P. 2012. Phytochemical screening and antioxidant activities of two selected 'bihi' fruits used as vegetables in darjeeling Himalaya. Int. J. Pharm. Pharm. Sci., 4(2): 567-574.

Huda-Faujan, N., Noriham, A., Norrakiah, A.S. and Babji, A.S. 2009. Antioxidant activity of plants methanolic extracts containing phenolic compounds. Afr. J. Biotechnol., 8(3): 48448.

Jain, A., Sinha, P. and Desai, N.S. 2014. Estimation of flavonoid, phenol content and antioxidant potential of Indian Screw tree (Helicteres isora L.). Int. J. Pharm. Sci. Res., 5: 13201330.

Jayachitra, A., Kirtiga, N. 2012. Study on antioxidant property in selected medicinal plant extracts. Int. J. Med. Arom. Plants, 2(3): 495-500.

Jecob, A. and Malpathak, N. 2004. Green hairy root cultures of Solanum khasianum Clarke - a new route to in vitro solasodine production, Curr. Sci., 87(10): 1442-1447.

Jian, L., Qing-Wang, L., Da-Wei, G., ZengSheng, H. and Wen-Zong, L. 2009. Antitumor and immunomodulating effects of polysaccharides isolated from Solanum nigrum Linne, Phytother. Res., 23(11): 1524-1530.

Khatodia, S. and Biswas, K. 2014. A comparative study of Hairy Root Culture induction efficiency in four medicinally important plants using Agrobacterium rhizogenes. Int. J. Curr. Microbiol. App. Sci., 3(5): 625633.

Kumar, S., Kumar, D., Saroha, K., Singh, N. and Vashishta, B. 2008. Antioxidant and free radical scavenging potential of Citrullus colocynthis (L) Schard, methanolic fruit extract. Acta Pharmacologica, 58: 215-220.

Lee, S.J. and Lim, K.T. 2003. Antioxidative eff ects of glycoprotein isolated from Solanum nigrum Linne on oxygen radicals and its cytotoxic effects on the MCF-7 cell. J. Food Sci., 68: 466470.

Lee, S.J. and Lim, K.T. 2006. 150 kDa glycoprotein isolated from Solanum nigrum L. stimulates caspase-3 activation and reduces inducible nitric oxide production in HCT-116 cells. Toxicol in Vitro., 20(7): 1088-1097.

Luximon-Ramma, A., Bahorun, T., Soobrattee, M.A. and Aruoma, O.I. 2002. Antioxidant activities of phenolic, proanthocyanidin and flavonoid components in extracts of Cassia fistula. J. Agric. Food Chem., 50: 5042-5047.

Mandal, S., Mallick, N., Mitra, A. 2009. Salicylic acid-induced resistance to Fusarium oxysporumf. sp. Lycopersici in tomato. Plant. Physiol. Biochem., 47: 642-649.

Murthy, H., Dijkstra, C., Anthony, P., White, D., Davey, M., Power, J., Hahn, E., Paek, K., 2008. Establishment of Withania somnifera Hairy Root Cultures for the Production of Withanolide A. J. Integrative Plant Biol., 50: 975-981. 
Muruhan, S., Selvaraj, S. and Vishwanathan, P. 2013. In vitro antioxidant activities of Solanum surattense leaf extract. Asian Pac. J. Trop. Biomed., 3(1): 2834.

Nguyen, H.L., Nguyen, H.A., Le, T.K. and Ton, N.T. 2014. An Effects of yeast extract and methyl jasmonate on the enhancement of solasodine biosynthesis in cell cultures of Solanum hainanense Hance. J. BioSci. Biotech., 3(1): 1-6.

Ooi, C., Syahida, A., Stanslas, J. and Maziah, M. 2012. Efficiency of different Agrobacterium rhizogenes strains on hairy root induction in Solanum mammosum. World J. Microbiol. Biotechnol., 29(3): 421430.

Pai, T.V., Sawant, S.Y., Ghatak, A. A., Chaturvedi, P. A., Gupte, A. M. and Desai, N. S. 2015. Characterization of Indian beers: chemical composition and antioxidant potential. J. Food Sci. Technol., 52(3): 1414-1423.

Pawar, P. and Maheshwari, V. 2003. Agrobacterium rhizogenes mediated hairy root induction in two medicinally important members of family Solanaceae. Indian $J$. Biotechnol., 3: 414-417.

Raju, K., Anbuganapathi, G., Gokulakrishnan, V., Rajkapoor, B., Jayakar, B. and Manian, S. 2003. Effect of dried fruits of Solanum nigrum LINN against CCl4-induced hepatic damage in rats. Biol. Pharm. Bull., 26(11): 1618-1619.

Rani, P. and Khullar, N. 2004. Antimicrobial evaluation of some medicinal plants for their anti-enteric potential against multidrug resistant Salmonella typhi. Phytother. Res., 18(8): 670-673

Rhodes, M., Payne, J., Hamill, J., Robins, R., 1987. Production of hyoscyamine by hairy root cultures of Datura stramonium. Planta Medica., 53: 474478.

Rodriguez, J., Segovia, R., Guerreiro, E., Derretti, F., Zamarbide, S.G. and Ertola, R. 1979. Production of solasodine by microbial hydrolysis of glycoalkaloids of Solanum eleagnifolium Cav. and its application to the synthesis of 16dehydropregnenolone acetate. $J$. Chem. Technol. Biotechnol., 29: 525530.

Saeed, N., Khan, M. R. and Shabbir, M. 2012. Antioxidant activity, total phenolic and total flavonoid contents of whole plant extracts Torilis leptophylla L. BMC Complement Altern. Med., 12: 1-12.

Shanks, J., Morgan, J. 1999. Plant hairy root culture. Curr. Opinion Biotechnol., 10: 151-155.

Sharma, M., Romana, M., Menaria, J., Devi, S. and Sheikh, M. 2014. In vitro antioxidant potential of various extracts of Solanum nigrum. The Pharmaceutical and Chem. J., 1(1): 69.

Singleton, V.L. and Rossi, J.A. 1965. Colorimetric analysis of total phenolics with phosphornolybdicphosphotungstic acid reagent. Am. J. Enol. Viticulture, 16: 144-158.

Somawathi, K., Rizliya, V., Wijesinghe, D. and Madhujith, W. 2014. Antioxidant Activity and Total Phenolic Content of Different Skin Coloured Brinjal (Solanum melongena) Trop. Agri. Res., 26(1): 152 - 161.

Sree, A., Rao, Y.R. and Mahapatra, S.N. 1982. A process for the conversion of solasodine 110 to 16dehydropregnenolone acetate. Res. Industry, 27: 326-328.

Subroto, M.A. and Doran, P.M. 1994. 
Production of steroidal alkaloids by hairy root of Solanum aviculare and the effect of gibberlic acid. Plant Cell Tissue and Organ Culture, 38(2): 93102.

Sudha, G., Sangeetha, P.M., Indhu shree, R. and Adivukkarasi, S. 2011. In vitro free radical scavenging activit y of raw pepino fruit Solanum muricatum aiton). Int. J. Curr. Pharm. Res., 3(2): 137-140.
Sundari, G.S., Rekha, S. and Parvathi, A. 2013. Phytochemical evaluation of three species of Solanum L. Int. J. Res. Ayurveda Pharm., 4(3): 420-425.

Zakaria, Z.A., Gopalan, H.K. and Zainal, H. 2006. Antinociceptive, antiinflammatory and antipyretic eff ects of Solanum nigrum chloroform extract in animal models. Yakugaku Zasshi, 26: 1171-1178.

\section{How to cite this article:}

Subhash Kudale, Swaroopa Ghatge, Anuja Shivekar, Chinmyee Sule and Neetin Desai. 2016. Comparative Study of Antioxidant Potential in Hairy Roots and Field grown Roots of Solanum nigrum L. Int.J.Curr.Microbiol.App.Sci. 5(8): 42-54.

doi: http://dx.doi.org/10.20546/ijcmas.2016.508.005 